\title{
Transformation of Consciousness: Decoding Conceptual Metaphors in Mira Bai
}

\author{
Amrita \\ Dept. of English, BPS Women University, Khanpur kalan, Sonipat-131305, Haryana, India \\ E-mail: amrita1177@gmail.com \\ Anisha (Corresponding author) \\ Dept. of English, BPS Women University, Khanpur kalan, Sonipat-131305, Haryana, India \\ E-mail: chugh_anisha@yahoo.com
}

Doi:10.7575/aiac.alls.v.7n.4p.211

URL: http://dx.doi.org/10.7575/aiac.alls.v.7n.4p.211
Received: $18 / 04 / 2016$

Accepted: 28/06/2016

\begin{abstract}
Mira Bai, a saint-poet of North India is an important figure in medieval Hindi literature. Her bhajan-s (songs) profoundly represent the transforming of consciousness working through conceptual metaphors which fall in the realm of religious poetry wherein target domains are generally abstract. Since, the working of the mind is more powerful than anything else, consciousness has become the central issue in modern philosophy of mind and metaphysics. Can we try to gauge abstract ideas and consciousness? What do we need to make such ideas explicit? What happens when the line between the abstract and the real becomes blur or transparent, especially with respect to spiritual experience? It is here that metaphors step in providing us glimpses into representational relation between mental processes, state of mind and the material world. Therefore, this present paper attempts to study conceptual metaphors which are replete in Mira Bai's poetry conforming to her spiritual journey. The paper is divided into three sections viz. Mira Bai, Understanding Conceptual Metaphor, A Study of Mira Bai's Selected Poetry.
\end{abstract}

Keywords: Mira, Metaphor, Religious poetry, Mapping

\section{Introduction}

The Indian Classical Tradition describes the four main objectives of human pursuit called purūsārtha i.e. Dharma (duty with compassion and righteousness), Artha (wealth and prosperity), Kāma (satisfying material desires), and Mokșa (liberation from material pursuits/salvation). Bhāmaha, an Indian logician and poetician from Kashmir, in his famous treatise Kāvyālamkāra, does echo these aforesaid aims of writing good poetry. While the ultimate aim of life is mokṣa (salvation), it cannot be attained without self-realisation (Chapter 1, kārikā-II). Out of the three basic paths provided for attaining salvation - karmayoga (action), jñānayoga (knowledge) and bhaktiyoga (devotion), the path of devotion is most plausible because it helps to get rid of $m \bar{a} y \bar{a}$ (worldly illusion) more fruitfully. Even an ordinary, illiterate person can follow this path of devotion easily. Mira Bai, the great saint-poet born in 1498 A.D. of North India carved herself a niche by traversing such a path singing bhajan-s (songs) which became popular among common masses, renouncing her family honour and comfort. She is known to have crossed boundaries of caste, creed and colour showing great courage to become a bhakta (devotee) with her dauntless devotion, surrendering to Lord Krishna. Her radiance of spirit, selfconfidence, evolved consciousness and concentrated effort to achieve the divine are certainly extraordinary. This paper attempts to investigate conceptual metaphors which are replete in her religious verses conforming to her spiritual journey.

\subsection{Mira's Life}

The journey of Mira's life starts from 1498 A.D. (Vikram Samvat 1555) in a village named Kudaki, near Medata, a small region of Marwad, Rajasthan in a Rajput family. Mira was the daughter of Ratan Singh Rathod and the granddaughter of Dudaji of Medata. Her mother died when she was about five to seven years old. It is said that Mira Bai could not experience the affection of her parents for long as her father was engaged in fighting against Mugals. However, Rao Dudaji, her grandfather, raised this beautiful child-princess with love. In 1516, Mira was married to Prince Bhoj Raj, son of Rana Sanga. In the absence of reliable information about Mira's death, the legends inform that Mira's body melted physically into the image of deity in the temple of Ranachor in Dwarka (Gujarat) around 1546 (Chaturvedi, 15).

It is said that during her childhood, Mira saw a wedding procession and asked her mother who her bridegroom would be. The mother innocently pointed to the idol that Mira was holding close to her bosom and said, 'That would be your groom'. From that time onwards, Mira started to adore the idol and accepted Shri Krishna as her divine husband (Kumar 4). Though she was married against her wishes to Rana Bhojaraj of Sisodia yet her dauntless devotion as well as surrender only to Lord Krishna, irrespective of her worldly relations, is what makes her a beacon of the sublime 
consciousness, lightening the minds of the masses through her bhajan-s; opening the doors of self-realization, liberation from all material desires, as well as transcendentalism. This ecstasy is felt in these lines:

False are these rubies and pearls,

False their glimmer and shimmer;

False are these ornaments; true is the Beloved's love. -L3 (Kumar, 50)

Therefore, Mira's love for the divine conforms to 'love for love sake'. Precious rubies and pearls do not hold any attraction for her. Levi (1997) puts it as, "Mira's bhajan-s, in Indian and Western notations are offered as a melodic outline of suggestion" (72). Therefore, her poetry offers multiple layers of meaning and a great scope for interpretation. Bly and Hirshfield (2004) praise this mystic saint-poetess in the following words:

"Millions have memorized and sung the poems of Mirabai's passion, each finding in her words some intimate and individual truth, and also

some companionship along the path of awakening. To read Mirabai

is to awaken more deeply into your own life" (xiii).

Hence, the abstract domain of her religious poetry gets cast into beautiful conceptual metaphors which provide a framework for an interesting study. It has been said:

"Love of money is the root of all evils but on the other side Love of

God is the root of dissolution of worldly ties that leads to emancipation

of life, that is to say, to eternal absolution. Love is the only way of

devotion which leads to recognition of self. This recognition of self

made Mira work for her salvation by singing the glory of Lord Krishna”.

(Mehta, 42)

\section{Understanding Conceptual Metaphor}

Language is a domain which offers multiple levels for study. It serves as a major stepping stone for the investigation of language comprehension and production. It is also worth mentioning that the systematic classification and observations provided by linguists and philosophers of language have given edge to the already focused discussions. Therefore, to decode the meaning accurately, role of context has also been a cause of debate since language processing can be viewed as an interactive system in which any type of contextual information can affect the nature of processing of any other piece of information; on the other hand, it is also viewed as a highly modular system comprising of autonomous subroutines, so that contextual information does not affect processing any particular subroutine (Swinney, 308). It is here, metaphor comes into play since it brings what Richards call "a shift, a carrying over of a word from its normal use to a new use" (Constable, 178-179) on the basis of "an implied analogy in which one thing is imaginatively identified with another dissimilar thing" (Cuddon, 117). The significance of metaphor germinated in Aristotle's Poetics who believed that:

"the greatest thing by far is to be a master of metaphor. It is the one thing

that cannot be learnt from others; and it is also a sign of genius, since a

good metaphor implies an intuitive perception of the similarity in dissimilar".

(Poetics, 1459 a)

In other words, metaphor is a way to "who we are and what kind of world we live in" (Kövecses, 2010: xi- xiii).

Aristotle understood the three-component structure of metaphor based on the analogy like a simile: the primum, secundum, and tertium comparationis, however, I. A. Richards termed these components as the tenor, vehicle and ground (1936: 93). This three-component structure can be understood by a simple example -- 'My house is Taj-Mahel' wherein Tenor (House) and Vehicle (Taj-Mahel) and the common ground 'beautiful' is visible at the surface structure. However, there are metaphors, especially in literature, which are implicit, for example 'Apollo's upward fire made every eastern cloud a silvery pyre' (Keats) wherein the metaphor has to be guessed from the allusion made to the Sun God since the ground of comparison is implicit. Max Black (1962) in his Interactionist Theory of metaphor reduces this three-component structure into two parts viz. focus (vehicle) and frame (tenor). Black (1962) is of the opinion that metaphors are not direct but an interaction of the correlative properties of likened concepts:

"The maker of a metaphorical statement selects, emphasizes, suppresses, and

organizes features of the primary subject by applying to it statements isomorphic

with the members of the secondary subject's implicative complex" (Black 1962).

The Semantic Field Theory by Eva F. Kittay (1987) observed that in a metaphor, structure of one semantic field induces a structure on another content domain. However, M. Black's ideas provided the ground for subsequent theoretic development which started to dominate since the 1980s, especially in George Lakoff's Theory of Conceptual Metaphor, which assumed that a metaphor is a mapping of knowledge from a source domain (sphere) to a target sphere, which 
results in numerous concrete manifestations (Lakoff, 1993). In Metaphors We Live By, George Lakoff and Mark Johnson argue that metaphors are pervasive in everyday life, not just in language, but also in thought and action (1980, 3). Metaphors are omnipresent and Lakoff writes that "metaphor is fundamentally conceptual and not linguistic in nature" (1993: 244) and especially when it comes to abstract experiences like "Today the leaves cry, hanging on branches swept by wind, / Yet the nothingness of winter becomes a little less' (W. Stevens) - herein the abstract concept is metaphorically structured, the activity is metaphorically structured, and, consequently, the language is metaphorically structured $(1980,5)$.

Therefore, borrowing words from Helen V. Shelestiuk, no other complex semiotic phenomenon has received such a broad theoretic coverage as metaphor. The list seems non-exhaustive starting from the Aristotle, Rousseau, Lomonosov, Hegel, Nietzsche, Cassirer, Ortega-y-Gasset, Ricouer and other prominent thinkers who have explored the ontological roots of metaphor the concept of metaphor has been developed by many deceased and living scholars as Max Mueller, A. Potebnya, I. A. Richards, M. Black, R. Jakobson, K. Burke, P. Wheelwright, C. Brook-Rose, L. J. Cohen, J. Searle, S. Levin, G. Lakoff, M. Johnson, R. Gibbs, A. Paivio, A. Ortony, T. Todorov, U. Eco, V. P. Grigoryev, N. D. Arutyunova, S. M. Mezenin (2006: 333) in philology and linguistics (including theory of literature, etymology, linguistic pragmatics, and cognitive linguistics).

In the present scope of work in this paper, the seminal work of Lakoff and Johnson has been taken as theoretical framework because conceptual metaphor theory arose with an aim to uncover systematic mappings at the supraindividual level, i.e. in our conceptual system (langue/competence), and these mappings are then used and applied in specific contexts for communicative purposes by speakers at the individual level (parole/performance). Mapping can be defined as the systematic set of correspondences between identical constituent elements of the source and the target domain. Many new elements of the target domain come from the source domain, which are not pre-existing. To know a conceptual metaphor is to know the set of mappings that applies to a given source-target pairing. Lakoff and Johnson believe that metaphorical concepts are extremely rich and complex which arise from physical, cultural and various other experiences. Therefore, metaphorical concepts can be grouped into three types:

(a) Structural Metaphors: It forms the biggest group. It works on highlighting/hiding phenomenon. In this type of metaphor, the source domain provides a relatively rich knowledge structure for the target concept. In other words, the cognitive function of these metaphors is to enable speakers to understand target 'A' by means of the structure of source 'B'. For example, Discussion is war. Herein, the feature of war is highlighted. Another example could be, the concept of time structured according to motion and space - Time is motion (Kövecses, 2010: 33).

(b) Ontological Metaphors: In this kind of metaphor, we conceive of our experiences in terms of objects, substances, and containers, in general, without specifying exactly what kind of object, substance, or container is meant (Kövecses: 2010, 33). For example, The world is full of art. Besides, human states and emotions can also be dubbed as containers. For example, He fell into a depression. An important group of ontological metaphors consists of personification. For example, Life betrayed me. Clive Cazeaux (2007), who specializes in metaphor and visual thinking in aesthetics, opines:

"Within metaphor, a distinction can be drawn between mere and ontological metaphor; whereas the former simply associates a physical concept with a metaphysical one, the latter recognizes that all concepts resonate with possible transpositions and, as such, brings to the fore the world-making power of speaking. Furthermore, ontological metaphor structures experience as an openness to . . movement between concepts" (51).

Ontological metaphors deal with rationality of our experiences. The range of these metaphors is enormous. Lakoff and Johnson (1980, 26-27) give the following factors to realize this type:

(i) Referring (ii) Quantifying (iii) Identifying Aspects (iv) Identifying Causes

(v) Setting Goals and Motivating Actions

(c) Orientational Metaphors: Orientational metaphors provide even less conceptual structure for target concepts than ontological ones (Kövecses, 2010: 35). They are strongly cultural in context. The structure is linear orienting them with respect to non-metaphorical linear orientations. These types of metaphors deal with spatial orientations: up-down, in-out, front-back, on-off, deep-shallow, central-peripheral (Lakoff and Johnson, 1980, 14). For example, mind is up/emotion is down.

\section{A Study of Mira Bai's Selected Verses}

Religious/spiritual poetry of the great Krishna's devotee Mira-Bai, is not only elegant and simple but also very distinct and classic, so much so that it captures everybody's attention universally. Either the person is a learned scholar or a commoner, both can enjoy the elements of spirituality in it with an open heart. Mira's transcendental thought fuses with nobility of nature and sublime love produces poetry of the sublime quality. 
The type of thought Mira demonstrates is equivalent to the moment of revelation of truth with intense aspiration for divine realization. This is what has forged into mystic transformation in her consciousness. To try to decipher such a realization casted into linguistic expression is not an easy task. However, examples have been culled from a large plethora of Mira Bai's verses and classified in concordance with the three conceptual categories of metaphors provided by Lakoff and Johnson.

\subsection{Structural Metaphors in Mira's Poetry}

- A cluster of phenomenal and conscious states can be expressed by a qualisign such as a tree. 'TREE' is a concept which is as primordial as the civilization itself. Therefore, it is a common source domain used in religious poetry. Mira says in The Way of the Tree:

"O mind, adopt the ways of the tree

And from the cares of the world become free.

Those who come to cut it, it does not hate,

Nor adores them who come to irrigate.

Even to those who hurl stones with force

It yields fruits, with no touch of remorse.

Gales and storms and the fury of rain

It suffers all, yet does not complain.",

(Sethi, 191)

In this example, the source domain (tree) provides a relatively rich knowledge structure for the target concept (devotee). Herein, the characteristics of a tree are conceptually highlighted. The Vedic School of thought believes that 'trees' are sacred and primary forms of living beings. Trees possess great knowledge, having witnessed the rise of civilization. A fruit bearing tree is a symbol of nurturing energies which has its roots in the earth with its crown dancing in the sky. It is a symbol of wisdom and patience. Carl Jung treats a tree as a symbol of self-fulfilment; androgyny. In the above cited example, there is a conceptual mapping of the concept of the ways of a tree to state metaphorically that a devotee should be forbearing like a tree. Concomitantly, as Jacobson rightly said in his famous essay Closing Statements: Linguistics and Poetics that in poetry, "where similarity is super induced upon contiguity, any metonymy is slightly metaphoric and any metaphor has a metonymic tint." (17), tree is used metonymically for a seer/saint.

Just as the seer's mind remains stable and unaffected in worldly joys and sorrows, rain or shine; imparts knowledge to everyone without any consideration of caste, creed, colour or thinking who is right or wrong; similarly, a devotee should follow the path of devotion making him/her free of all doubts, sensual pleasures, and rising above material longings or emotional turbulence. Mira, herself does attain such a state of mind; a journey from ignorance to consciousness.

- In Mira's I Bought Govind..., there is a beautiful transposition of the various steps of making a trade through the scales:

Sister, I have bought Govind in the market,

You only speak of it secretly,

But I proclaim it openly, beating a drum.

You say it was expensive,

But I say it was cheap,

And I measured it out on the scales.

I would offer my body,

I would offer my life,

For a prize beyond all price.

O Lord of Mira, grant her Thy sight

According to Thy promise in her former birth.

(Alston 41)

Mira, in these lines, uses the metaphor of 'BUY-SELL' and believes that the price she is paying to buy 'the Cherished' is actually nothing significant. Her body and life can certainly be offered to get the prize of love of Govind. The source domain is 'the act of shopping in the market' which has metaphorically been mapped to the target domain of 'offering oneself as a price' for attaining Shree Krishna's love. A similar metaphor can be traced in George Herbert's poetry, which is full of tortured self-doubt, agonized examination of motivations and complaints like in the poem The Pearl:

Ifly to thee, and fully understand

Both the main sale and the commodities;

And at what rate and price I have thy love,

With all the circumstances that may move. 
Herein, the Christian belief is represented by recalling God's promise or presence, in typical psalm style resolving in a neat couplet at the end of the poem. Thematically, there is an attempt to balance everyday life and God; later the speaker has to choose between pleasures of senses, social and career achievements and God's love.

On the contrary, Mira proclaims her love openly and she is ready to pay any price to meet her Lord. The words marketscales-prize work as conceptual keys creating the prism of layered meaning in this conceptual metaphor. Scales, whether physical or abstract, represent the dynamics in human brain which contain extensive nested frequencies, with the phase of lower frequencies (material) modulating the amplitude of higher frequencies in an upward progression across the frequency spectrum. Mira finds an upward progression (spiritual) in her longing to meet the Supreme Being. All material assets are spendable, inexpensive, of no value (cheap) before the foremost prized union with Govind. Herein, one kind of activity has been structured in terms of another kind of activity or experience. The highlighting of the activity of trade enables understanding of target A by means of the structure of source B, thereby making it a structural metaphor.

\title{
3.2 Ontological Metaphors in Mira's Poetry
}

Such metaphors involve the status of entity on something that does not have that status inherently. The concept of 'love' is used as a source domain since human relationships share warmth, closeness and interaction. Many other emotions and attributes do relate to this primordial emotion. Lakoff and Johnson believes that related concepts can be placed along a gradient of their centrality in the definition of an emotional concept, such as love; some of them appear to be inherent parts of the conception of love (such as liking and affection), some of them are only loosely associated with it, in that they are a part of some idealized model of love (such as friendship or respect), and some fall in between (such as caring) (cf. Kövecses, 1988, 1990, 1991a).

- In the poem, My Love is Reserved for Girdhara, Mira's linguistic expression has been catapulted by conceptual mapping from the concrete to the abstract especially noticeable in L-11-12 of the poem:

\author{
My love is reserved for Girdhara Gopal \\ And for no one else. L-2 \\ $\cdots$ \\ I left brothers and relatives \\ And all I possessed. \\ I felt joy in the company of the devotees, \\ On beholding the world I wept. \\ I planted the creeper of love \\ And watered it with my tears. - L12 (Alston 40)
}

This is a reversal of the general formula of personification wherein abstract is given human attributes. The source domain is 'creeper' (concrete) and the target domain is 'love' (abstract).

The five factors listed by Lakoff and Johnson for ontological metaphors can be identified here: Referring - Girdhara Gopal (The Supreme One); Quantifying - (leaving) brothers and relatives, possessions; Identifying Aspects: reservation, Identifying Cause: company of the devotees; Setting Goals: planted the creeper; Motivating Actions watered it with (my) tears.

This example makes it evident that the concept of belonging governs a person's ontology: their view of the parameters of things, the lines and points at which one thing becomes something else. It could be said to determine a person's ecological awareness: their sense of 'what belongs to me' and 'what is beyond or outside of me'. Besides, ontological metaphors dub human states and emotion as containers. Herein, the concept of primary and subordinate emotions like 'love-joy' and 'love-weeping-tears' construct structures of experience, which Clive Cazeaux (2007) calls "transpositions" creating a movement between concepts which makes these lines a fine example of ontological metaphor.

- In Mira's The Divine Washerman, another example can be investigated, wherein act of WASHING clothes by a washer-man has accounted as source domain. This act of washing has been mapped conceptually to the abstract target domain i.e. purifying the mind for spiritual growth and development :

"If Master, the washerman, washes your mind,

It will never be soiled again. 
Break the chains of attachment, O fool,

And transcend the bondage of your body.

Annihilate the five and the twenty-five;

Kindle the lamp of your temple within.

With remembrance as the soap,

And love as the water,

Your mind, cleansed of all blemish,

With virtue will shine.

So deftly, will the washerman scrub it clean,

Even a speck of dirt it shall not gather again.

(Sethi 42)

Herein, the five characteristics listed by Lakoff and Johnson for ontological metaphors can be identified again: Referring - Master, the Washerman (The Supreme One); Quantifying - the five and the twenty-five; all blemish; Identifying Aspects : the mind-soiled, chains of attachment; Identifying Cause: soap, water; Setting Goals: scrub it clean; Motivating Actions - remembrance $\rightarrow$ virtue .

Metaphorically, these lines state that the Master is an adept washerman who can cleanse our mind of all its impurities. The quantum of impurities is provided by the number five and twenty-five which refers to the five passions i.e. lust, anger, greed, attachment and ego; twenty-five refers to the manifestations of the each of the five elements of the human body in this phenomenal world (prakriti-s).

In order to understand the beauty of this conceptual calibration, there is a need to glean some basics from Sānkhya philosophy. In Sānkhya, Purūṣa and Prakṛiti are the two governing principles of the universe. Purūṣa stands for "consciousness", the Spirit, which is inactive and not subject to change whereas Prakriti stands for "Nature", the phenomenal world which is active and subject to change. Purūṣa is also identified with an individual's true and eternal Self. Prakriti includes both the outer world and the ever-fluctuating inner world of the mind. Prakriti has three primary constituents/ manifestations viz. Sattva (lucidity), Rajas (activity) and Tamas (inertia). It is Buddhi (the intellect) which further controls Ahamkāra (ego), Manas (the mind), Five sense organs (cognitive instruments), Five action instruments (speaking, holding, moving, procreating, eliminating), Subtle elements (sound, touch, form, taste, odour) and Five gross elements (earth, fire, water, air, ether).

These aforesaid elements and instruments blemish the character and through them dirt of material pleasures get accumulated, consequently, the mind gets soiled. Mira uses a vocative "O fool" to give a wakeup call to those who are lost in worldly pleasures. She urges them to break the bondages of the phenomenal world by invoking this beautiful conceptual metaphor - The master washes the disciple's mind with compassion and recollection; with simran (remembrance), in the same fashion as 'soap' and 'water' wash the dirt on clothes in a fashion which will never be covered by dross again. Echoes of the Bhagavada Gita, interestingly, can be traced in this ontological metaphor which says:

When his thought ceases, checked by the exercise of discipline,

He is content within self, seeing the self through himself.

It is noteworthy that concepts here themselves work as agents allowing the linguistic expression to objectify experiences with a sense of boundary and classifying the substance inherent with their characteristics - making it again an unparallel example of ontological metaphor.

\subsection{Orientational Metaphors in Mira Bai’s Poetry}

Lakoff and Johnson (1980) feel that "no metaphor can ever be comprehended or even adequately represented independently of its experiential basis." The experience on which an orientational metaphor is based, is directly emergent physical experience or one drawn from the socio-cultural domain. For example, 'John is at the peak of his career or John fell into depression' - here, 'peak' has the experience of UP and 'fell' shows an experience of DOWN. It is interesting to note that such metaphorical orientations are not arbitrary. They have a strong basis not only in our physical experience of polar oppositions like up-down, in-out, near-far, deep-shallow etc., but also they are rooted in cultural experience which certainly does vary from culture to culture. Such metaphors generally work vertically giving rise to various subordinate set of metaphors - like in some cultures 'the future' is in front of us, whereas in others it is in the back. Systemic coherence, functioning in the organic whole of conceptualization concretizing into linguistic expression, is a factor which helps to select one metaphoric expression over the other. 
"Mother-in-law is sleeping on the terrace,

And sister-in-law in the courtyard.

My Beloved rests within the chambers above.

How am I to go and awaken Him?

...

Awake, O friend, lost in delusion,

Mira went and met her Beloved

And became free from the grip of illusion.

(Sethi 43)

In these above quoted lines, the first four lines provide space referents with reference to physical as well as culturally conditioned cognitive concepts. There is an interesting use of prepositions as linguistic referent indicating location and space- on, in, within; and at the same time creating a relationship between nominal entities.

This metaphor uses a subset of multiple conceptual mappings viz. Maya (illusionary phenomenal world) is Mother-in law, Trișna (worldly desires) is Sister-in-law and Krishna is the beloved (husband). The wife, Mira wants to be in unison with her husband. As per the old Indian tradition and custom, she must meet him alone in his chamber with subtlety. However, she finds it very challenging because her path is obstructed by her mother-in-law and sister-in law and the way to her husband's chamber is through the courtyard (the human body) and the terrace (glabella in supraorbital ridge or the eye centre). This situation demonstrates the experiential basis for Mira, apparently, is DOWN $\downarrow$

Maya in Atharvaveda also stands for 'wisdom and power enabling its possessor to create, devise, contrive, effect, or do something.' This concept is also transposed to mother-in-law. She can contrive against Mira, the daughter-in-law and not let her meet her husband. The relationship between them is tricky and mother-in-law could create false illusions or devise ways to bring adversity for Mira in order to sweep chances of union of both husband and wife. This again threats DOWN $\downarrow$ for Mira.

According to Wendy Doniger (1986), "to say that the universe is an illusion (maya) is not to say that it is unreal; it is to say, instead, that it is not what it seems to be, that it is something constantly being made. Maya not only deceives people about the things they think they know; more basically, it limits their knowledge" (119). On the contrary, the concluding lines of the poem speak of the success of Mira in meeting her beloved husband. She is sharing it with her friend with joy that not only she has succeeded to overcome the challenges of meeting her husband but also she has attained freedom from the clutches of illusion. In other words, her soul meets the divine abandoning the desires of the phenomenal world.

This is an experiential state of being UP $\uparrow$.

Therefore, this metaphor unravels an exquisite example of orientational metaphor. It is not only culled from sociocultural backdrop but we can also trace vertical movement from DOWN to UP.

- Another verse The Coffer with the Poisonous Snake also presents a beautiful orientational metaphor. It demonstrates how sometimes we may associate abstract ideas (like awareness) that do not have a location with a particular space:

"Rana sent a gold coffer of complicated ivory;

But inside a black and green asp was waiting,

"It is a necklace that belonged to a great Queen!"

I put it around my neck; it fit well.

It became a string of lovely pearls, each with a moon inside.

My room then was full of moonlight, as if the full moon

Had found its way in through the open window." (Bly \& Hirshfield, 46)

Generally speaking, sending gifts to family and friends has been a tradition across cultures. Whether a pauper, or a king; sending or receiving gifts of any kind is always memorable. Rana, the brother-in-law of Mira, sends an attractive gold coffer as a gift but the coffer contains an asp waiting to spring outside to bite Mira symbolizing hate of Rana who is conspiring against her. Therefore, space orientations of INSIDE $\downarrow$ and OUTSIDE $\uparrow$ are clearly visible. It is not out of place to mention that the venom of an asp is deadly. The act of Rana reminds one of Shakespeare's Antony and Cleopatra, wherein Cleopatra attempts suicide-by-asp:

With thy sharp teeth this knot intrinsicate Of life at once untie: poor venomous fool Be angry, and dispatch. 
Prepositions like inside, around, full of, through, grammatically play referents of space in Mira's verse. Adding to it, 'Ivory' is White $\uparrow$ whereas the 'Asp' is Black $\downarrow$ which is also contrastive in the phenomenal world and 'green' is metaphorically associated with jealousy.

Besides, gold, a transitional metal, stands an emblem of the power of the sun which denotes wealth, culture and prestige. The colour of gold is associated with masculine energy which also symbolises immutability, eternity and perfection. Besides, since gold is purified by fire, it is taken sacred, taking one to the path of spirituality. On the contrary, silver or a pearl or moon is linked to feminine energy. The moon stands for sensitivity, well-being, as well as for growing sense of 'awareness'.

Gold coffer (source domain -- concrete) is conceptually mapped to material temptations (target domain -- abstract); complicated ivory is conceptually mapped on the whirlpool of material pleasures; necklace is superimposed on the glitter of phenomenal experiences; string of lovely pearls is conceptually given contours of various acts of faith in the divine; my room is the spirit; moonlight becomes a source domain for the target - awareness; a journey from ignorance to knowledge and realization which is coming through the window (the mental eye). Therefore, significant subsets of metaphoric entities are interlaced to weave the fabric of this conceptual metaphor.

Consequently, this example is remarkably outstanding in representing UP-DOWN of the two realms of existence viz. 'Asp' representing EVIL/DEATH $\downarrow$ whereas beautiful pearl necklace shining like full moon representing VIRTUE/LIFE $\uparrow$. Again, there is a vertical movement in space dimensions from Down $\downarrow$ to Up $\uparrow$ establishing it as an orientational metaphor.

\section{Conclusion}

Metaphors in Mira's poetry, like most of the saint-poets in Indian religious tradition, work at both the levels - form and meaning. Her poetry traverses through metaphors to reach the destination of self-awakening. Rising from the materialistic domain of the world where she endured the criticism and taunts; she reached the spiritual domain of poetry where only the transcendental love matters. The distance between the two ends is covered through metaphors which do not merely serve the purpose of filigree but cross the boundary where metaphors connote the spiritual philosophy of Mira where she expresses the boundless love for Lord Krishna. It is here that we see how consciousness is transformed. In this way, metaphors are not only an outline and a framework but also seeds of ideas and thoughts from which the beautiful flowers of poetry flourish.

A number of cross-linguistic similarities in conceptualization show that metaphor may be independent of a particular language. Consciousness is also universal and so are the linguistic expressions which move generally from concrete to abstract domains in religious poetry (for universal metaphors see Kövecses, 2010: 195-210). Technically speaking, the choice of words used by the saint-poet Mira Bai plays a very important role in the making of meaning. The stylistic markers help the reader to decode the message which Mirabai is trying to acculturate across. Thus, studying metaphors in Mira Bai's verses illustrate how metaphors provide us an opportunity to comprehend the layers of meaning, various connotations, implications and suggestions inherent and embedded at the conceptual-cognitive level.

\section{References}

Alston, A.J. (2008). The Devotional Poems of $M r b$ : Translated with Introduction and Notes. Delhi: Motilal Banarsidas Publishers Private Limited.

"Animal Symbolism: Meaning of the Cat". (16 July 2015). <http://www.whats-your-sign.com/cat-animalsymbolism.html>

Aristotle. Poetics. (14 ${ }^{\text {th }}$ April 2010). Trans.S.H.Butcher. <http./libertyonline/hypermall>.

Behari, B. (1937). The Story of Mira Bai. Gorkhpur: Gita Press.

Black, M. (1962). Models and Metaphor. Ithaca: Cornell University Press.

Bly, Robert and Jane Hirshfield. (2004). Mirabai: Ecstatic Poems. Boston: Beacon Press.

Cazeaux, C. (2007). Kant, Cognitive Metaphor and Continental Philosophy. Routledge.

Chaturvedi, P. (2008). $M r$ b i ki Pad val . 22 $2^{\text {nd }}$ ed. Ilhabad: Hindi Sahitya Samalan.

Constable, J. (2001). (Ed.) I.A. Richards and His Critics Vol:10. London: Routledge.

Cuddon, J.A. (1998). The Penguin Dictionary of Literary Terms and Literary Theory. Penguin Books.

Doniger O'Flaherty, Wendy. (1986). Dreams, Illusion, and Other Realities. New York: University of Chicago Press.

Gibbs, R. W. (1994). The Poetics of Mind: Figurative thought, language, and understanding. UK: Cambridge University Press.

Jakobson, R. (1960). Closing Statements: Linguistics and Poetics, Style in language, (ed.) T.A. Sebeok, New-York.

Kittay, Eva F. (1987). Metaphor: Its Cognitive Force and Linguistic Structure. Oxford: Oxford University Press.

Kovesces, Z. (2010). Metaphor: A Practical Introduction. Oxford: Oxford University Press.

Kumar, K. (2004). $M r$ : The Emancipated Soul. New Delhi: Harman Publishing House.

Lakoff, G., and Johnson, M. (1980). Metaphors we Live By. Chicago and London: The University of Chicago Press. 
Lakoff, G. (1993). "The Contemporary Theory of Metaphor". Metaphor and Thought. Ed. Andrew Ortony. USA: Cambridge University Press. 202-251.

Lakoff, G., and Johnson, M. (1980). The Metaphorical Structure of the Human Conceptual System. Cognitive Science, 4, 195-208.

Levi, L. (1997). Sweet on My Lips: The Love Poems of Mirabai. New York: Cool Grove Press.

Mehta, S.S. n.d. (---). A Monograph on Mirabai; The Saint of Mewad. Bombay: General Books.

Ortony, A. (1993). Metaphor and Thought. $2^{\text {nd }}$ ed. UK: Cambridge University Press.

Richards, I.A. (1936). The Philosophy of Rhetoric. London: Oxford University Press.

Richards, I.A. (1974). "Pseudo-Statements". Twentieth Century Criticism: The Major Statements. Delhi: Light and Life Publishers.

Sharma, Pt. Sh. (1962). Bh mahavirachit Kavyalamkara. Patna: Bihar Rashtrabhasha Parishad.

Sethi, V.K. (2009). Mira: The Divine Lover. $4^{\text {th }}$ Ed. Punjab: Radha Soami Satsang Beas.

"Thoughts on Some Things - Symbolism: The Ocean". (16 July 2015). $<$ http://thoughtsonsomethings.blogspot.in/2013/03/symbolism-ocean.html>

Shelestiuk, Helen V. (2006). Approaches to Metaphor: Structure, Classifications, Cognate Phenomena. Semiotica 1611/4. 333-343. <http://shelestiuk.narod.ru/publications/Approaches-to-metaphor.pdf $>$

Swinney, D. (1981). The Process of Language Comprehension; an approach to examining issues in cognition and language. Cognition 10.307-312.<http://lcnl.ucsd.edu/LCNL_main_page/Publications_PDF/1981_Swinney.pdf>

The Poetics: Aristotle on the Art of Poetry. $<\mathrm{http}: / /$ www.authorama.com/the-poetics-23.html>

Weber, Edmund. (15 $5^{\text {th }}$ Sep. 2009). "Hindu Feminism Part 1: The Emancipation of Mirabai." <http://web.unifrankfurt.de/irenik/relkultur129.1.pdf>. 